\title{
Counting sperm does not add up any more: time for a new equation?
}

\author{
Linda Lefièvre ${ }^{1}$, Kweku Bedu-Addo², Sarah J Conner ${ }^{1}$, Gisela S M Machado-Oliveira ${ }^{3}$, \\ Yongjian Chen ${ }^{4}$, Jackson C Kirkman-Brown ${ }^{5}$, Masoud A Afnan ${ }^{5}$, Stephen J Publicover ${ }^{3}$, \\ W Christopher L Ford ${ }^{1}$ and Christopher L R Barratt ${ }^{1}$
}

${ }^{1}$ Reproductive Biology and Genetics Group, Division of Reproductive and Child Health, The Medical School, University of Birmingham, Edgbaston, Birmingham B15 2TT, UK, ${ }^{2}$ Department of Physiology, School of Medical Sciences, Kwame Nkrumah University of Science and Technology, Kumasi, Ghana, ${ }^{3}$ School of Biosciences, University of Birmingham, Birmingham B15 2TT, UK, ${ }^{4}$ The Center of Reproductive Medicine, Peking University Third Hospital, Beijing 100083, China and ${ }^{5}$ Assisted Conception Unit, Birmingham Women's Hospital, Birmingham B15 2TG, UK

Correspondence should be addressed to C L R Barratt who is now at Division of Reproductive and Child Health, The Medical School, University of Birmingham, Room WX 1.30, West Wing, Birmingham B15 2TT, UK; Email: c.l.barratt@bham.ac.uk

\begin{abstract}
Although sperm dysfunction is the single most common cause of infertility, we have poor methods of diagnosis and surprisingly no effective treatment (excluding assisted reproductive technology). In this review, we challenge the usefulness of a basic semen analysis and argue that a new paradigm is required immediately. We discuss the use of at-home screening to potentially improve the diagnosis of the male and to streamline the management of the sub-fertile couple. Additionally, we outline the recent progress in the field, for example, in proteomics, which will allow the development of new biomarkers of sperm function. This new knowledge will transform our understanding of the spermatozoon as a machine and is likely to lead to non-ART treatments for men with sperm dysfunction. Reproduction (2007) 133 675-684
\end{abstract}

\section{Introduction}

This review starts with the premise that there is a clear need to dramatically improve our understanding of the cellular and molecular basis of sperm function. This knowledge is fundamental for two key developments in male fertility: firstly, to provide the basis for effective diagnostic tools and, secondly, to facilitate the study of the physiology of abnormal/dysfunctional cells, which is central for developing rational, non-ART therapy. We initially discuss the developments in male fertility testing with particular reference to the potential role of at-home testing in the sub-fertile patient's pathway. Secondly, we discuss advances in potential markers involved in key physiological processes, such as capacitation and sperm proteomics, which are likely to transform our understanding of the normal functional cell and lead to improvements in diagnosis and developments of rational therapy.

Epidemiological data show that 1:7 couples are classed as sub-fertile (Hull et al. 1985, Templeton et al. 1990). Sperm dysfunction is the single most common cause of infertility and affects approximately 1:15 men (HFEA 2005, www.hfea.gov.uk). Studies using semen assessment as the criteria for sub-fertility (sperm concentration $<20 \times 10^{6} / \mathrm{ml}$ ) show that 1:5 18-year-olds are classed as sub-fertile (Andersen et al. 2000). This is a high proportion of the population compared with other prevalent diseases such as diabetes (2.8\% of the population; Wild et al. 2004). Thus, male sub-fertility is a very significant global problem and, what is most worrying is that the recent reports suggest that its prevalence is increasing (Sharpe \& Irvine 2004).

\section{Improving and evaluating the diagnosis of male fertility, in particular, sperm dysfunction}

There is an urgent requirement to develop new and robust tests of sperm function to accurately diagnose male infertility. The value of traditional semen parameters (concentration, motility and morphology) in the diagnosis and prognosis of male infertility has been debated for 60 years and, perhaps not surprisingly, the debate intensifies (see Bjorndahl \& Barratt 2005 for detailed discussion). There are clear issues over concordance with standardized procedures (Holt 2005, Pacey 2006) with differences undoubtedly leading to uncritical reporting of results and thus precipitous 
decline in usefulness of the tests. A stark warning presents itself: if the professionals cannot successfully turn around the current low performance in the majority of Andrology laboratories, semen analysis will become undervalued and a redundant procedure. Unquestionably, even with appropriate quality assurance, traditional semen parameters can only provide a limited degree of prognostic and diagnostic information for the infertile couple (Tomlinson et al. 1999), primarily at the lower ranges of the spectrum (Comhaire 2000). The insanity that surrounds perceived absolute values, e.g. $5 \%$ 'normal' forms is just that - insanity. Continual discussion and generation of putative cut-off values will lead to further irrelevant and misleading information.

It is, therefore, necessary to develop simple, robust and effective tests of sperm function. Yet, despite the plethora of potential assays available, results have been very disappointing (Muller 2000, Aitken 2006). Recent data suggest that only three potential tests of sperm function have sufficient data to support their routine use: penetration into cervical mucus (or e.g. hyaluronate; Ivic et al. 2002), measurement of reactive oxygen species production/lipid peroxidation (Ford 2004, Williams \& Ford 2005) and estimate of sperm chromatin/DNA damage (Seli \& Sakkas 2005); however, promising initial data for the latter is now being questioned (see Bungum et al. 2004, Gandini et al. 2004, Erenpreiss et al. 2006, Makhlouf \& Niederberger 2006).

After decades of research, the primary reason for the paucity of effective and robust estimate of sperm function is our limited basic understanding of the functioning of the spermatozoon (Ford 2001, Conner et al. 2007). Additionally, there has been inappropriate and uncritical use of the current tools (Barratt 1995, Tomlinson et al. 1999, Conner et al. 2007). However, there are a number of new developments which promise to transform our diagnostic and treatment pathways (for examples see Aitken 2006, Jimenez-Gonzalez et al. 2006, Publicover et al. 2007). Two of these are 1) development of at-home testing and 2) biomarkers for sperm function.

\section{A new paradigm in male fertility diagnosis: the development of at-home testing}

Many men find the production of a semen sample for infertility investigations an embarrassing, difficult and stressful experience. To add to this, there can be a significant waiting time for an initial appointment at the hospital and an additional time delay before the results are available. All these factors heighten the anxiety associated with infertility investigations, often delaying investigations and subsequent treatment and consequently reducing the chances of success (HFEA 2005, www.hfea.gov.uk). The development of an over-thecounter home sperm test, which would allow the patient to obtain an assessment of fertility potential at their own convenience in the comfort of their home, has a number of benefits including potentially increasing the number of men who are tested and speeding up the diagnosis.

Several putative tests are available but the primary questions regarding home sperm testing are accuracy and reliability. In our laboratories, we have concentrated on developing a test (Fertell; Bjorndahl et al. 2006) based on assessing the concentration of progressively motile sperm, which is one of the most predictive parameters for estimating natural fertility in both sub-fertile (review Tomlinson et al. 1999) and normal couples (Larsen et al. 2000, Zinaman et al. 2000; Fig. 1). In addition, we wanted an assay that would provide an assessment of the functional capacity of the sperm as a small proportion of men with normal semen parameters (e.g. $>10$ million progressively motile sperm $/ \mathrm{ml}$ semen) have dysfunctional sperm (see Barratt et al. 1989). Briefly, we mimicked penetration into human cervical mucus in vitro using hyaluronic acid, a known cervical mucus substitute for sperm function studies (Aitken et al. 1992). Our analysis show that the test is accurate $(\sim 95 \%)$ and patients find it easy to use (see Bjorndahl et al. 2006 for details).

Currently, we do not know what proportion of men with normal semen parameters but defective cells (so called hidden male factor patients - see Barratt \& Publicover 2001) would be detected by our assay. However, as the number of these men is small, it is not a pivotal issue. What is a critical factor is where (and how) such home testing fits in the diagnostic pathway. Providing home testing is accurate then it should have a well-defined place in the screening of sub-fertile couples. The evaluation of diagnostic tests is now subject to renewed critical examination (Gluud \& Gluud 2005). Diagnostic tests can be used as replacement, triage or add-on with their usefulness being dependent on a large number of factors (Bossuyt et al. 2006). Home sperm testing has not been evaluated in this critical manner and thus we are uncertain where in the pathways it fits best. Our analysis suggests it as a firstline initial investigation. Based on our preliminary data of $\sim 95 \%$ accuracy, the likelihood is that men who test positive (red line - thus $>10$ million progressively motile sperm $/ \mathrm{ml}$ semen) will not require a semen assessment unless specific, rare circumstances suggest otherwise. The couples (if the female is normal) may be encouraged to try longer (Steures et al. 2006). Men with a red line would certainly be suitable for intrauterine insemination and possible in vitro fertilization (IVF), but not intracytoplasmic sperm injection (ICSI). This paradigm would have a significant cost saving $(\sim 28 \%$ men in our tertiary referral centre would be positive) as no initial screening semen analysis would be required. Men who were negative (no red line) would urgently require a highquality comprehensive semen assessment (WHO 1999). This diagnostic pathway requires validation to determine if home testing can be used to improve the pathway of 


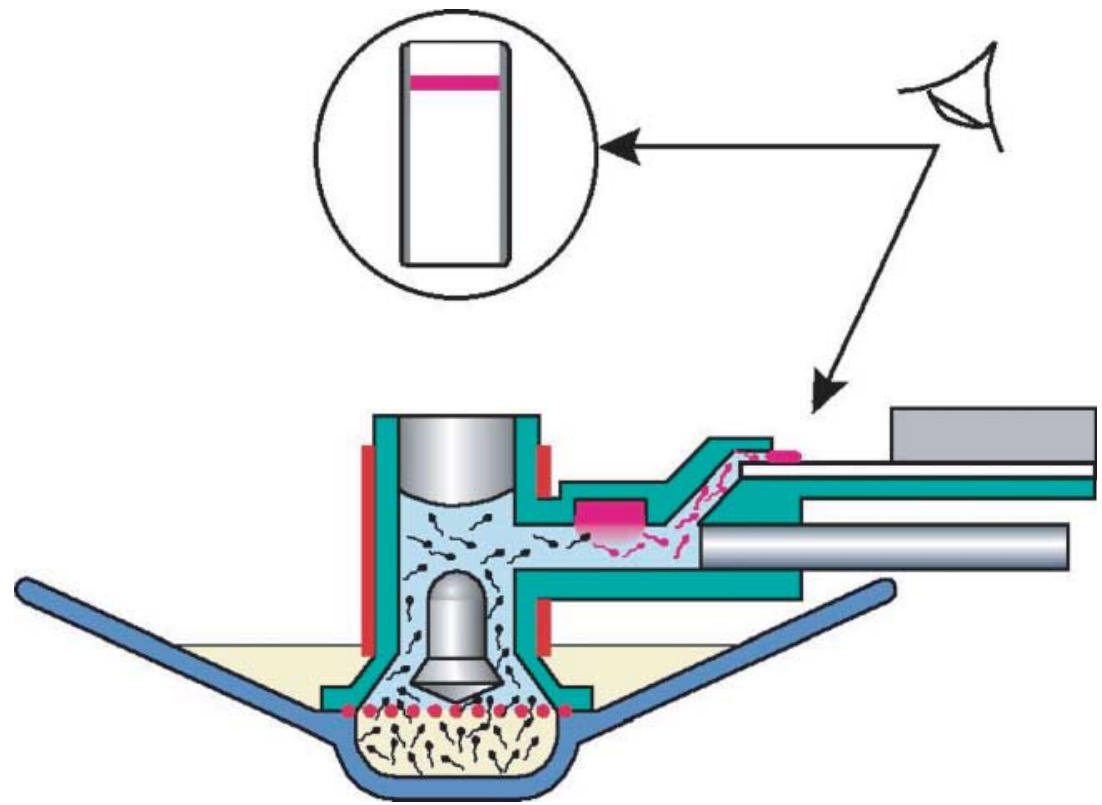

Figure 1 Diagrammatic representation of the home sperm test. Progressively motile sperm swim from semen (yellow) into hyaluronate (HA) solution (blue) via a mesh (red dotted line). Sperm are then released into capillary channel, labelled with anti-CD 59 colloidal gold conjugate (red sperm) and trapped on the nitrocellulose strip where a visible line is formed if sufficient numbers of progressively motile sperm have migrated into the HA solution. Red solid line around the green capsule is the heater to keep the cells at $37^{\circ} \mathrm{C}$. A red line is visible if $>10$ million motile cell $\mathrm{s} / \mathrm{ml}$ of semen are present in the ejaculate (Adapted from Bjorndahl et al. 2006). infertility investigations and provide cost-effective analysis (Fig. 2).

Home fertility testing for the man is now a reality and combined with the plethora of tests available for women: urinary luteinizing hormone (Barratt et al. 1989, Robinson et al. 1992), follicle-stimulating hormone dipsticks (www.fertell.co.uk) and complex urinary monitors; there is the potential, as yet untested, to revolutionize the diagnostic and treatment pathways for the sub-fertile couple.

\section{Biomarkers for sperm function}

\section{Events associated with sperm capacitation}

After deposition in the female tract, mammalian sperm undergo a number of functional and structural changes termed 'capacitation', which render the cells competent to fertilize. Capacitation can also be induced in vitro by incubation, usually for some hours, in suitable medium. The most widely accepted functional definition of in vitro capacitation is acquisition of ability to undergo acrosome reaction in response to a biological agonist, such as zona pellucida or progesterone. Studies on sperm incubated under capacitating conditions have revealed numerous biochemical and physiological changes that accompany the process including an efflux of plasma membrane cholesterol, an increase in the activity of adenylate cyclase (both soluble and membrane localized), elevated levels of CAMP and protein kinase A (PKA) activity, a rise in intracellular $\mathrm{pH}$, hyperpolarization of membrane potential and increased serine/ threonine and tyrosine phosphorylation of some proteins (Tash \& Means 1983, Leclerc et al. 1996, Cross 1998, Osheroff et al. 1999, Lefièvre et al. 2002, Visconti et al. 2002, O'Flaherty et al. 2004, Fraser et al. 2005, Moseley et al. 2005). These observations provide useful indicators of the occurrence of capacitation in spermatozoa in vitro, but it is still far from clear how the various events relate to each other or whether all of them must occur for the acquisition of fertilization competence to occur. It is likely that sperm possess the ability to regulate the signalling pathways involved in capacitation, thus minimizing over-capacitation and premature acrosome reaction (Visconti et al. 2002, Ecroyd et al. 2004, De Jonge 2005, Fraser et al. 2005), but it is not clear to what extent the changes that have been observed in capacitating cells are reversible and whether they are capacitation endpoints or part of the capacitation process (such that reversal does not prevent subsequent induction of acrosome reaction).

We have recently demonstrated that upon transfer of cells from non-capacitating to capacitating media (CM), PKA activity, serine/threonine phosphorylation and $\left[\mathrm{Ca}^{2+}\right]_{\mathrm{i}}$-signalling 'switch' between minimum and maximum rapidly (as fast as detectable; Fig. 3; Bedu-Addo et al. 2005, Moseley et al. 2005). In contrast, the occurrence of tyrosine phosphorylation of tail proteins requires up to $3 \mathrm{~h}$ to reach its maximum. Progesteroneinduced acrosome reaction also rises much more slowly, possibly because of the latency of tyrosine phosphorylation of head proteins (Fig. 3; Bedu-Addo et al. 2005). We have also shown that different $C M$ vary strikingly in their efficacy as IVF fertilization media was shown to accelerate sperm capacitation where both tyrosine phosphorylation and acrosome reaction reached a maximum after only $90 \mathrm{~min}$ (Moseley et al. 2005). This effect did not seem to be associated with enhanced activation of PKA or increased levels of serine/threonine phosphorylation suggesting factor(s) acting through signalling pathways other than the well-characterized 


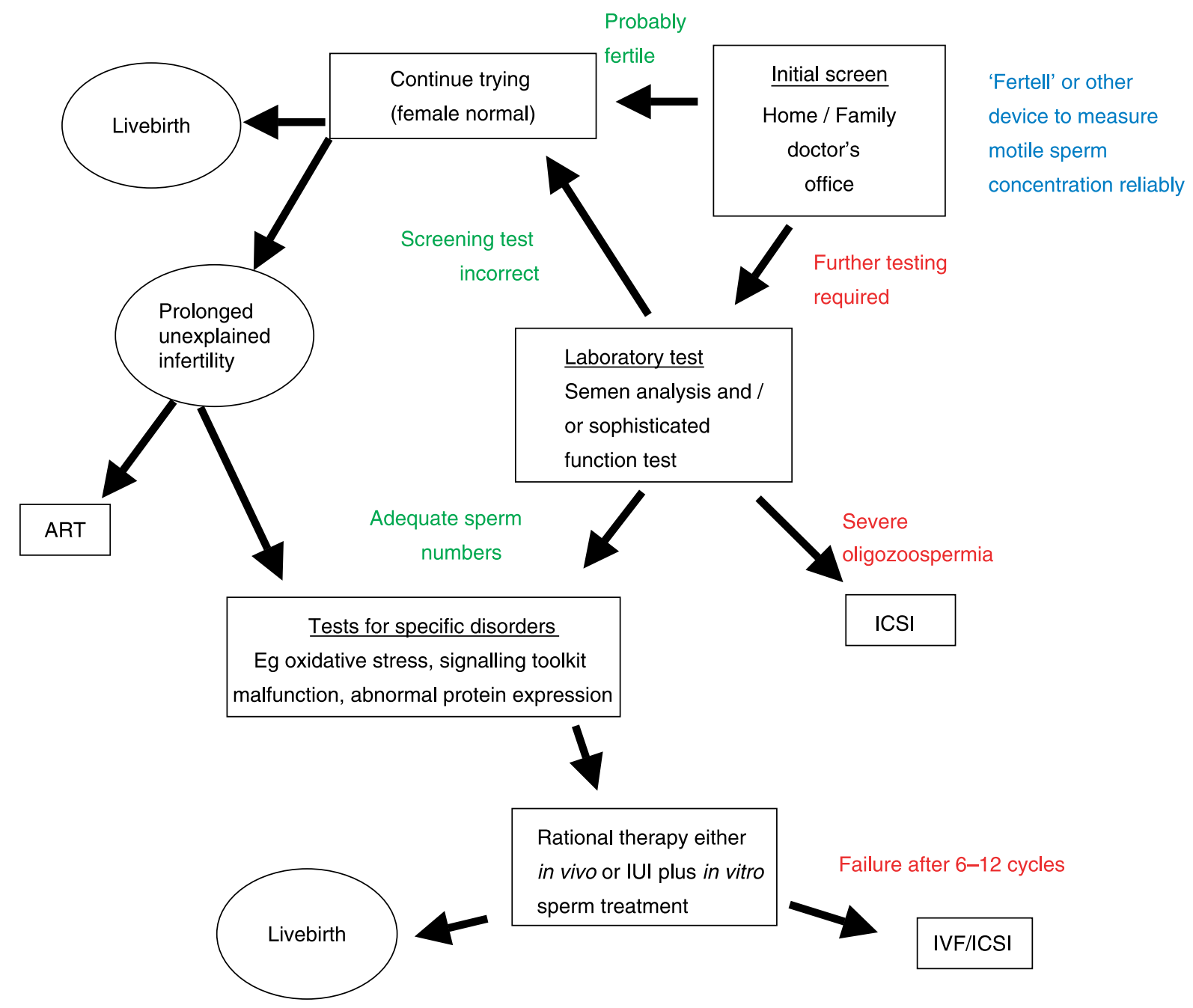

Figure 2 A new paradigm for sperm testing. The first step is a simple screening test (Fertell or similar), designed to distinguish men who are probably fertile from those where further investigation is indicated. If the man's semen passes the test and his partner is normal they can continue trying to conceive. The minority that experience prolonged infertility should be offered ART but in future improved tests that lead to other effective treatment. If the semen fails the screening test then the result will need to be confirmed in the laboratory, perhaps by a standard semen analysis supplemented by a sperm function test. If the screening test proves to be incorrect (i.e. the man has a large number of motile cells), the couple can continue trying. In some cases, men may have severe defects e.g. severe oligozoospermia, globozoospermia, in which case immediate referral for ICSI will usually be the best option. However, most men who reach this stage are likely to have low but adequate sperm numbers with impaired sperm function. Proteomics and other novel research tools will allow development of a battery of tests to diagnose the underlying cause of poor sperm function and to direct them to appropriate therapy (see section - Biomarkers of sperm function in text). It may be possible to treat the man, but it may be easier to develop ways to treat sperm in vitro to increase success rates in IUI. Only if appropriate therapy remains unsuccessful after a reasonable period (probably 6-12 cycles depending on age and other factors), would the couple be referred for IVF/ICSI.

activation of soluble adenylyl cyclase/cAMP/PKA (Moseley et al. 2005). Moreover, we have also demonstrated that, in human spermatozoa, progesterone-induced $\left[\mathrm{Ca}^{2+}\right]_{i}$ signalling, protein serine/ threonine phosphorylation, protein tyrosine phosphorylation and progesterone-induced acrosome reaction are all reversibly regulated by the external environment (Fig. 3; Bedu-Addo et al. 2005). Human spermatozoa are therefore capable of repeated and reversible cycles of many of the events that occur in response to capacitating conditions and have a high degree of plasticity and adaptability in their responses to events which signal ovulation.

Tyrosine phosphorylation of sperm proteins is a wellestablished and widely-used marker for cells undergoing capacitation (Visconti et al. 1995a, 1995b, Leclerc et al. 1996, Osheroff et al. 1999). In our recent experiments, we showed that when spermatozoa were incubated in $\mathrm{CM}$ for $6 \mathrm{~h}$ and then resuspended in CM without bicarbonate or $\mathrm{CM}$ without albumin for an additional hour, the cells lost their ability to undergo acrosome reaction (Bedu-Addo et al. 2005). However, the absence of either albumin or 


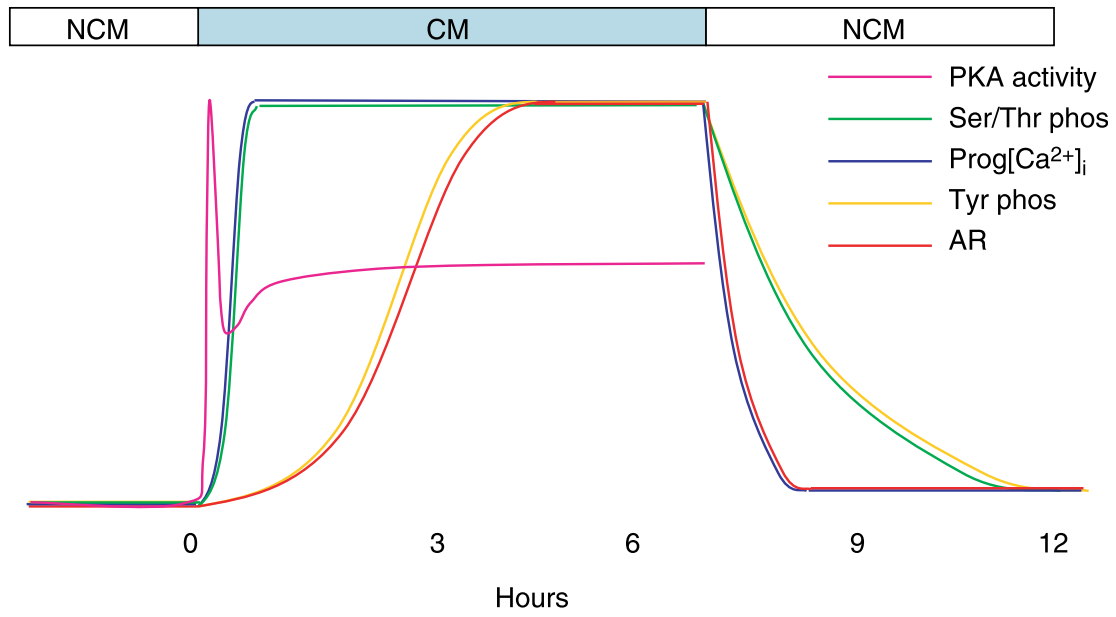

Figure 3 Proposed sequence of events during induction and reversal of capacitation in vitro. Under capacitating conditions, PKA activity (pink line), serine/threonine phosphorylation (green line) and $\left[\mathrm{Ca}^{2+}\right]_{i}$-signalling (blue line) 'switch' between minimum and maximum in minutes. In contrast, acquisition of competence to undergo progesterone induced AR (red line) and the occurrence of tyrosine phosphorylation (yellow line) of tail proteins requires up to $3 \mathrm{~h}$ to reach maximum. PKA levels drop over the subsequent 5 min before reaching a plateau at $30 \mathrm{~min}$. Tyrosine phosphorylation (yellow line) and progesterone-induced acrosome reaction (AR, red line) rises more slowly, taking up to $3 \mathrm{~h}$ to reach a maximum. Upon return to NCM, serine/threonine tyrosine phosphorylation reverses slowly (approximately $3 \mathrm{~h}$ ), but the progesterone-induced $\left[\mathrm{Ca}{ }^{2+}\right]_{i}$ signal falls to minimal levels within minutes. Progesterone-induced AR also falls to levels similar to those seen in uncapacitated cells in less than an hour of re-suspension. The kinetics of this change are shown to follow those of the $\left[\mathrm{Ca}^{2+}\right]_{i}$ response such that AR is dependent on the development of tyrosine phosphorylation during capacitation and on the decay of the $\left[\mathrm{Ca}^{2+}\right]_{\mathrm{i}}$ signal during decapacitation. (Adapted from Bedu-Addo et al. 2005, see also Bedu-Addo et al. 2007).

bicarbonate did not prevent protein tyrosine phosphorylation in these cells. Levels of tyrosine phosphorylation were comparable to the ones observed in CM medium (Bedu-Addo et al. 2005). These results support the use of sperm protein tyrosine phosphorylation as a marker of cells undergoing capacitation (Visconti et al. 1995a, 1995b, Leclerc et al. 1996, Osheroff et al. 1999), but suggest that tyrosine phosphorylation is not a diagnostic marker of capacitated cells.

There is little doubt that failure of capacitation is a cause of infertility in a subset of patients. However, the complexity of the process involved is such that it is not yet possible to identify a reliable marker of capacitated (competent to fertilize) sperm. The complexity of 'capacitation' may even be such that no single reliable marker exists.

\section{Calcium oscillations in sperm - a new signalling system?}

We have recently reviewed and discussed at length the exciting developments in calcium $\left(\mathrm{Ca}^{2+}\right)$ signalling in the spermatozoon (Harper \& Publicover 2005, JimenezGonzalez et al. 2006, Publicover et al. 2007). We believe that sperm intracellular calcium $\left(\left[\mathrm{Ca}^{2+}\right]_{\mathrm{i}}\right)$ oscillations are functionally significant, modulating flagellar activity in a way that promotes functional sperm motility changes (Harper \& Publicover 2005). Intriguingly, the ability of cells to generate these complex $\left[\mathrm{Ca}^{2+}\right]_{i}$ signals does not seem to be noticeably related to capacitation. Perhaps, this should not be surprising. The prime marker of capacitation is acrosome reaction, and the $\mathrm{Ca}^{2+}$ store mobilization that occurs during oscillations raises $\left[\mathrm{Ca}^{2+}\right]_{i}$ in the neck and midpiece regions of the sperm and affects the flagellum but does not induce acrosome reaction (Harper et al. 2004, Bedu-Addo et al. 2007). Similarly, hyperactivation, though often associated with capacitation, can be induced separately and occurs by a separate, $\mathrm{Ca}^{2+}$-dependent, signalling pathway (Marquez \& Suarez 2004). Our recent findings suggest that two factors, prior filling of the $\mathrm{Ca}^{2+}$ store in the sperm neck region and nitrosylation of sperm proteins, predispose the sperm to generate $\left[\mathrm{Ca}^{2+}\right]_{i}$ oscillations and consequent effects on flagellar activity. Thus, the ability of the sperm to generate complex $\mathrm{Ca}^{2+}$ signals is apparently regulated, but by mechanisms separate to those that underlie classical 'capacitation'. Identification of features that are diagnostic of this regulation may provide a new way to identify sperm that are capable of generating complex patterns of flagellar activity and provide the first step to being able to manipulate these patterns using specific drugs.

The sperm proteome: the potential for new biomarkers of male fertility and a transformation in our understanding of the spermatozoon as a machine

The comprehensive and systematic identification and quantification of proteins expressed in cells and tissues are providing important and fascinating insights into the dynamics of cell function (Chu et al. 2006, Rifai et al. 2006). Yet, although spermatozoa are ideal to study from a proteomic perspective, until very recently, there have 
been relatively few studies examining the proteome of the spermatozoa (Ainsworth 2005, Conner et al. 2007). By virtue of the rudimentary technology available, initial human sperm proteomic studies were relatively crude. Many studies used antisperm antibody sera in an attempt to detect potential novel (and functional) sperm targets for male contraception. Unfortunately this rational approach met with limited success (Naaby-Hansen et al. 1997, Shetty et al. 1999, Shibahara et al. 2002; review in Conner et al. 2007). Perhaps surprisingly, recent studies employing more sophisticated proteomic profiling have similarly failed to identify interesting targets (Bhande \& Naz 2007). It is likely that we need to redefine the nature of immunological infertility before this strategy will yield meaningful results. The more recent experiments have followed four main themes: (1) identification of proteins associated with specific events in sperm function, (2) examination of specific structures and associated signalling complexes, (3) whole proteome investigation and (4) comparison with normal versus abnormal (fertile versus sub-fertile).

Identification of proteins associated with specific events in sperm function. It has been 12 years since the discovery of tyrosine phosphorylation as a putative marker of capacitation (Visconti et al. 1995a, 1995b; see above), but the role of these proteins and their sequence of activation is still very sketchy with the exception of only a small number of candidate proteins (see Naz \& Rajesh 2004). Until recently, we were a long way from obtaining even a minimal 'picture' of events. However, several recent proteomic studies have provided a wealth of information which has the capacity to transform our potential understanding of protein changes associated with capacitation. For example, examining the phosphoproteome of human sperm during capacitation has provided some interesting novel targets. In addition to A-kinaseanchoring proteins (AKAPs; AKAP3 and AKAP4) and calcium-binding tyrosine-phosphorylation regulated protein, several other interesting proteins: heat shock protein 70 and $90 \alpha$ suggested as being involved in sperm egg interaction and valosin-containing protein (VCP/p97) a member of the ATPases associated with various cellular activities were detected (Ficarro et al. 2003). Interestingly, tyrosine phosphorylation of VCP/p97 regulates its subcellular localization and its localization changes from the neck to the head after capacitation (Ficarro et al. 2003). Several other groups of proteins such as enzymes, structural proteins and channels were also identified. Moreover, with the pivotal role of tyrosine phosphorylation in sperm capacitation it is important to identify the kinases involved. Lalancette et al. (2006) used an affinity chromatography approach combined with proteomic analysis on the cytosolic fraction of bovine sperm to enrich tyrosine kinase activity. Tyrosine kinases from three families were identified: Src (Lyn), Csk and Tec (bmx, Btx). In addition, other important proteins involved in different cellular events associated with sperm, such as capacitation and acrosome reaction were also identified (a total of 126 proteins). These proteins include: actin polymerization, chaperones, proteases, proteases inhibitors, metabolism, vesicle transport/membrane fusion, signal transduction, sperm-egg interaction and structural proteins. Surprisingly, a number of sperm RNA binding/transport proteins were also identified. In view of the recent suggestions of the potential role of RNA in early embryo developed, these could be an important surreptitious finding (Miller et al. 2005).

Stein et al. (2006) performed a selected proteomic analysis of mouse sperm of the regions that are likely to be involved in mediating sperm-egg interactions. Subcellular fractionation included enrichment of acrosomal contents and plasma membrane. In the acrosomal contents, 166 proteins were identified and, as expected, two of the largest groups were enzymes and their inhibitors and secretory proteins. Twenty-five percent of the proteins were novel. Two hundred twenty-nine proteins were identified from the vesicle fraction and 171 from biotinylation fraction. Interestingly, a significant number of the biotinylated proteins were ion channels, most of which had unknown function.

Examination of specific structures and associated signalling complexes. Nomura \& Vacquier (2006) performed immunoprecipitation experiments for soluble adenylate cyclase (sAC) to determine the proteins associated with $\mathrm{SAC}$ in the sea urchin flagellum. Ten proteins were tightly associated with sAC including guanylyl cyclase and cGMP specific phosphodiesterase (PDE5A). This approach provides a critical starting point demonstrating the potential role in protein phosphorylation and ion channel activities in sperm motility.

There are a number of studies examining the proteomic composition of the $9+2$ arrangement of the cilium. For example, Pazour et al. (2005) performed a proteomic analysis of Chlamydomonas reinhardtii flagella documenting the basic building blocks (for updates go to http://labs.umassmed.edu/chlamyfp/index.php). As the $9+2$ structure is relatively conserved throughout evolution, you would expect a similar proteome across species. Yet, although there is remarkable conservation across the phyla, detailed proteomic studies on, for example, the flagella of trypanosomes show surprising diversity among the 300 or so proteins forming the axoneme (Broadhead et al. 2006). Interestingly, comparing the proteomes of Trypanosoma brucei with C. reinhardtii classified only 49 proteins to be common. 249 proteins were present but not in C. reinhardtii and 203 proteins present in $C$. reinhardtii but not in T. brucei. Further studies are required to determine the role of 'organism specific elaborations'. Sperm proteomic techniques are still refining the composition of the axonemal structures, e.g. outer dynein arms (Hozumi et al. 2006). Such studies, used in comparisons across species, are likely to provide a detailed understanding of the basic molecular motor apparatus. For example, comparisons between mutants of Chlamydomonas can 
provide a powerful analysis of the defects present in the sperm of sub-fertile men and identify potential interactions of novel signalling complexes (see Zhang et al. 2004). Detailed imaging of the flagella motion (Ohmuro \& Ishijima 2006) will allow a clear understanding of how the dynamics of the signalling complexes affect waveform. In addition to the studies on the axoneme, there is also data on the sperm accessory structures (fibrous sheath, outer dense fibres). For example, Cao et al. (2006) identified 50 proteins associated with these structures dramatically enhancing our knowledge of localization of both expected and unexpected complexes. This study confirmed that the fibrous sheath is a dynamic structure having a fundamental role in signalling, metabolism and oxidative stress. A proteomic study of the human fibrous sheath identified a unique ADP/ATP carrier protein and seven glycolytic enzymes previously unreported in the human fibrous sheath confirming that the fibrous sheath is a complex structure intimately involved in energy transduction (Kim et al. 2007). Such studies will lead to a new understanding of sperm metabolism and open exciting avenues for research potentially addressing 'old' questions such as the role of glucose in sperm energy metabolism (Ford 2006).

Whole proteome investigation. So far, there are only two studies addressing the complete human sperm proteome (Johnston et al. 2005, Martinez-Heredia et al. 2006). Using a two-dimensional gel analysis followed by mass spectrometry, Martinez-Heredia et al. (2006) identified 98 different proteins. A significant number was associated with proteosome turnover providing further evidence for the existence of the proteosome in human sperm function (Sutovsky et al. 2004). Interestingly, the second most abundant group of proteins were those involved with transcription, protein synthesis and turnover and protein transport/folding. As the spermatozoon is supposed to be transcriptionally and translationally silent, this may reflect a role for sperm RNA in the egg (see above and Lalancette et al. 2006, Martinez-Heredia et al. 2006). Alternatively, the dogma that the sperm are translationally dormant may need to be reassessed in the light of recent preliminary evidence that they can both synthesize and turnover proteins (Gur \& Breitbart 2006).

Johnston et al. (2005) adopted a direct one-dimensional SDS-PAGE approach with liquid chromatography tandem mass spectrometry performed on the various protein bands from detergent soluble and insoluble fractions of human spermatozoa. They identified 1760 proteins with high confidence - representing $76 \%$ of the proteins predicted to be in sperm. This represents the most comprehensive sperm proteome to date. Interestingly, the greatest number of proteins characterized was either novel proteins or proteins for which no ontology was available providing a wealth of new information. Of particular interest was the significant number of tissuespecific proteins as these could potentially be used as targets for male contraception. It is likely that a number of studies reporting/refining the whole-sperm proteome will become available in the next 12 months allowing a comprehensive first draft of the mature cell to be available. In addition to studies on the sperm proteome, a number of authors have examined the protein profile of seminal plasma. In the most comprehensive study to date, Pilch \& Mann (2006) identified 923 proteins with high confidence. Not surprisingly, the most abundant proteins were those associated with involvement in clot formation, metabolism and protection of the sperm cell. Potentially, this dataset could be used for biomarker discovery for testicular cancer, prostate cancer and for male infertility. Once a subset of protein markers is available, it may be feasible to perform protein chip diagnoses as used for cancer (Ciordia et al. 2006).

Comparison with normal versus abnormal (fertile versus sub-fertile). In our laboratory, we have been using proteomic strategies to identify defects in sperm function responsible for fertilization (Lefièvre et al. 2003, Pixton et al. 2004, reviewed Conner et al. 2007). Specifically, we are interested in identifying differences in sperm protein expression between control (fertile) men and patients with spermatozoa that failed to fertilize oocytes in vitro. Our initial studies showed, surprisingly, relatively little intra- and inter-donor variation and we have categorized one man (Pixton et al. 2004) where we identified 20 differences from the control that we are confident would represent true differences. Examination of five more men has found several consistent differences in protein expression levels (Conner et al. 2007) but further studies are required to determine if these differences relate to sperm function and where in the pathways these defects are manifested. Interestingly, with the clear need to identify (and improve) the fertility potential of animals in the agricultural industry, there is a concentration of effort to identify factors responsible for high fertility. For example, a study in bulls showed a significant effect of seminal plasma proteins on the function of the sperm, i.e. seminal plasma from high fertility bulls can act to improve the fertilizing potential of low-fertility bulls (Henault et al. 1995). Detailed proteomic studies of accessory gland fluids have shown consistent differences in high-/low-fertility groups, where four interesting proteins were identified: bovine seminal plasma $30 \mathrm{kDa}$ (sperm capacitation), osteopontin (sperm-oolema interaction), phospholipase A2 (acrosome reaction) and spermadhesin Z13 (sperm motility) as contributing to the higher fertility (Moura et al. 2006, $2007 a, 2007$ b). Examination of fertility in bulls is a very powerful approach as it allows in vitro studies to be complemented with data in vivo. Such complementary experiments cannot be performed in humans. The identification of proteins in the accessory glands of bulls contributing to fertility will allow a detailed understanding of how the sperm cell is modified by extrinsic factors. 


\section{How can all this detailed information be used to improve diagnosis and treatment of male infertility?}

There has been a dramatic increase in our knowledge of the protein composition of the spermatozoon, its structures and the surrounding fluids (epididymal, vesicular, prostate) contributing to its function. Additionally, we have preliminary insight into the signalling complexes involved in key physiological processes, e.g. capacitation and the regulation of sperm motility. The difficulty is that this knowledge represents only but a starting point, somewhat analogous to knowing all the genes in the human genome but uncertain of their role and interactions. Detailed physiological experiments are required to fully understand the biological function of these proteins (and complexes) in the mature cell and its interaction with its functional environment - the female tract and human egg. The data generated by proteomic analysis is leading to a dramatic increase in our understanding (and by its nature re-evaluation) of sperm cell function. As the current methods to assess sperm function are inadequate, a key objective will be to develop more effective biomarkers as has been done in other diseases (reviewed in Rifai et al. 2006). For example, if we can successfully adopt redox proteomics to sperm then we may be better able to identify men who will benefit from antioxidant therapy. If we apply critical validation methods to evaluate these new biomarkers, we can expect a dramatic change in the way we diagnose male fertility.

In addition, knowledge of the cell proteome (combined with metabolomics) will allow us, for the first time, to be able to develop rational therapies for sperm dysfunction. Remarkably, although, male infertility is an important health issue, there are no drug treatments to enhance sperm function that have been shown to be effective in randomized controlled trials (Kamischke \& Nieschlag 2002, cf. Greco et al. 2005). The only treatment option for the sub-fertile man is IVF/ICSI. ART is very expensive, invasive, has limited success, a number of side effects, is not widely available, and poses significant concerns about the long-term health of children (Maher 2005; review Hansen et al. 2005). This means that, put simply, as a result of our ignorance of the causes of sperm dysfunction, we are currently subjecting an increasing proportion of women to inappropriate invasive therapy in order to treat their partners. Hopefully, in the near future, perhaps using high throughput screening tools, we will be able to exploit our new knowledge base to develop and test new drug regimes for the enhancement of sperm function and avoid unnecessary ART treatment.

\section{Acknowledgements}

The authors wish to thank the patients and donors who participated in our research and the staff at the Assisted
Conception Unit, Birmingham Women's Hospital, as well as the Functional Genomics Laboratory of the University of Birmingham. Work presented in this manuscript was supported by Fonds de la Recherche en Santé du Québec (LL), MRC (SJP), Wellcome Trust (SJP) Wellcome Trust (CLRB), Genosis (CLRB). CLRB is a member of the Scientific Advisory Board of Genosis Ltd. This review is based on a lecture presented by CLRB at the CFAS in Ottawa, Canada on 16th November 2006. The authors declare that there is no conflict of interest that would prejudice the impartiality of this scientific work.

\section{References}

Ainsworth C 2005 Cell biology: the secret life of sperm. Nature 436 770-771.

Aitken RJ 2006 Sperm function tests and fertility. International Journal of Andrology 29 69-75.

Aitken RJ, Bowie H, Buckingham D, Harkiss D, Richardson DW \& West KM 1992 Sperm penetration into a hyaluronic acid polymer as a means of monitoring functional competence. Journal of Andrology 13 44-54.

Andersen AG, Jensen TK, Carlsen E, Jorgensen N, Andersson AM, Krarup T, Keiding N \& Skakkebaek NE 2000 High frequency of suboptimal semen quality in an unselected population of young men. Human Reproduction 15 366-372.

Barratt CL 1995 On the accuracy and clinical value of semen laboratory tests. Human Reproduction 10 250-252.

Barratt CL \& Publicover SJ 2001 Interaction between sperm and zona pellucida in male fertility. Lancet 358 1660-1662.

Barratt CL, Osborn JC, Harrison PE, Monks N, Dunphy BC, Lenton EA \& Cooke ID 1989 The hypo-osmotic swelling test and the sperm mucus penetration test in determining fertilisation of the human oocyte. Human Reproduction 4 430-434.

Bedu-Addo K, Lefièvre L, Moseley FL, Barratt CL \& Publicover SJ 2005 Bicarbonate and bovine serum albumin reversibly 'switch' capacitation-induced events in human spermatozoa. Molecular Human Reproduction 11 683-691.

Bedu-Addo K, Barratt CL, Kirkman-Brown JC \& Publicover SJ 2007 Patterns of $\left[\mathrm{Ca}^{2+}\right]_{i}$ mobilization and cell response in human spermatozoa exposed to progesterone. Developmental Biology 302 324-332.

Bhande S \& Naz RK 2007 Molecular identities of human sperm proteins reactive with antibodies in sera of immunoinfertile women. Molecular Reproduction and Development 74 332-340.

Bjorndahl L \& Barratt CL 2005 Semen analysis: setting standards for the measurement of sperm numbers. Journal of Andrology $\mathbf{2 6} 11$.

Bjorndahl L, Kirkman-Brown J, Hart G, Rattle S \& Barratt CL 2006 Development of a novel home sperm test. Human Reproduction 21 145-149.

Bossuyt PM, Irwig L, Craig J \& Glasziou P 2006 Comparative accuracy: assessing new tests against existing diagnostic pathways. British Medical Journal 332 1089-1092.

Broadhead R, Dawe HR, Farr H, Griffiths S, Hart SR, Portman N, Shaw MK, Ginger ML, Gaskell SJ, McKean PG et al. 2006 Flagellar motility is required for the viability of the bloodstream trypanosome. Nature 440 224-227.

Bungum M, Humaidan P, Spano $M$, Jepson $K$, Bungum L \& Giwercman A 2004 The predictive value of sperm chromatin structure assay (SCSA) parameters for the outcome of intrauterine insemination, IVF and ICSI. Human Reproduction 19 1401-1408.

Cao W, Gerton GL \& Moss SB 2006 Proteomic profiling of accessory structures from the mouse sperm flagellum. Molecular and Cellular Proteomics 5 801-810.

Chu DS, Liu H, Nix P, Wu TF, Ralston EJ, Yates JR III \& Meyer BJ 2006 Sperm chromatin proteomics identifies evolutionarily conserved fertility factors. Nature 443 101-105. 
Ciordia S, de Los Rios V \& Albar JP 2006 Contributions of advanced proteomics technologies to cancer diagnosis. Clinical and Translational Oncology 8 566-580.

Comhaire F 2000 Clinical andrology: from evidence-base to ethics. The 'E' quintet in clinical andrology. Human Reproduction 15 2067-2071.

Conner SJ, Lefièvre L, Kirkman-Brown JC, Michelangeli F, JimenezGonzalez C, Oliveira GM, Pixton KL, Brewis IA, Barratt CLR \& Publicover SJ 2007 Understanding the physiology of pre-ferilisation events in the human spermatozoa-a necessary prerequisite to developing rational therapy. Reproduction 563 237-256.

Cross NL 1998 Role of cholesterol in sperm capacitation. Biology of Reproduction 59 7-11.

Ecroyd H, Asquith L, Jones RC \& Aitken RJ 2004 The development of signal transduction pathways during epididymal maturation is calcium dependent. Developments in Biologicals 268 53-63.

Erenpreiss J, Bungum $M$, Spano $M$, Elzanaty S, Orbidans J \& Giwercman A 2006 Intra-individual variation in sperm chromatin structure assay parameters in men from infertile couples: clinical implications. Human Reproduction 21 2061-2064.

Ficarro S, Chertihin O, Westbrook VA, White F, Jayes F, Kalab P, Marto JA, Shabanowitz J, Herr JC, Hunt DF et al. 2003 Phosphoproteome analysis of capacitated human sperm. Evidence of tyrosine phosphorylation of a kinase-anchoring protein 3 and valosin-containing protein/p97 during capacitation. Journal of Biological Chemistry 278 11579-11589.

Ford WC 2001 Biological mechanisms of male infertility. Lancet 357 $1223-1224$

Ford WC 2004 Regulation of sperm function by reactive oxygen species. Human Reproduction Update 10 387-399.

Ford WC 2006 Glycolysis and sperm motility: does a spoonful of sugar help the flagellum go round? Human Reproduction Update $\mathbf{1 2}$ 269-274.

Fraser LR, Adeoya-Osiguwa S, Baxendale RW, Mededovic S \& Osiguwa OO 2005 First messenger regulation of mammalian sperm function via adenylyl cyclase/cAMP. Journal of Reproduction and Development 51 37-46.

Gandini L, Lombardo F, Paoli D, Caruso F, Eleuteri P, Leter G, Ciriminna R, Culasso F, Dondero F, Lenzi A et al. 2004 Full-term pregnancies achieved with ICSI despite high levels of sperm chromatin damage. Human Reproduction 19 1409-1417.

Gluud C \& Gluud LL 2005 Evidence based diagnostics. British Medical Journal $330724-726$.

Greco E, Romano S, lacobelli M, Ferrero S, Baroni E, Minasi MG, Ubaldi F, Rienzi L \& Tesarik J 2005 ICSI in cases of sperm DNA damage: beneficial effect of oral antioxidant treatment. Human Reproduction 20 2590-2594.

Gur Y \& Breitbart H 2006 Mammalian sperm translate nuclearencoded proteins by mitochondrial-type ribosomes. Genes and Development 20 411-416.

Hansen M, Bower C, Milne E, de Klerk N \& Kurinczuk JJ 2005 Assisted reproductive technologies and the risk of birth defects - a systematic review. Human Reproduction 20 328-338.

Harper CV \& Publicover SJ 2005 Reassessing the role of progesterone in fertilization-compartmentalized calcium signalling in human spermatozoa? Human Reproduction 20 2675-2680.

Harper CV, Barratt CL \& Publicover SJ 2004 Stimulation of human spermatozoa with progesterone gradients to simulate approach to the oocyte. Induction of $\left[\mathrm{Ca}^{2+}\right]_{i}$ oscillations and cyclical transitions in flagellar beating. Journal of Biological Chemistry 279 46315-46325.

Henault MA, Killian GJ, Kavanaugh JF \& Griel LC Jr 1995 Effect of accessory sex gland fluid from bulls of differing fertilities on the ability of cauda epididymal sperm to penetrate zona-free bovine oocytes. Biology of Reproduction 52 390-397.

Holt WV 2005 Is quality assurance in semen analysis still really necessary? A spermatologist's viewpoint Human Reproduction 20 2983-2986.
Hozumi A, Satouh Y, Makino Y, Toda T, Ide H, Ogawa K, King SM \& Inaba K 2006 Molecular characterization of Ciona sperm outer arm dynein reveals multiple components related to outer arm docking complex protein 2. Cell Motility and the Cytoskeleton 63 591-603.

Hull MG, Glazener CM, Kelly NJ, Conway DI, Foster PA, Hinton RA, Coulson C, Lambert PA, Watt EM \& Desai KM 1985 Population study of causes, treatment, and outcome of infertility. British Medical Journal 291 1693-1697.

Ivic A, Onyeaka H, Girling A, Brewis IA, Ola B, Hammadieh N, Papaioannou S \& Barratt CL 2002 Critical evaluation of methylcellulose as an alternative medium in sperm migration tests. Human Reproduction 17 143-149.

Jimenez-Gonzalez C, Michelangeli F, Harper CV, Barratt CLR \& Publicover SJ 2006 Calcium signalling in human spermatozoa: a specialized 'toolkit' of channels, transporters and stores. Human Reproduction Update 12 253-267.

Johnston DS, Wooters J, Kopf GS, Qiu Y \& Roberts KP 2005 Analysis of the human sperm proteome. Annals of the New York Academy of Sciences 1061 190-202.

De Jonge C 2005 Biological basis for human capacitation. Human Reproduction Update 11 205-214.

Kamischke A \& Nieschlag E 2002 Diagnosis and treatment of male infertility. In Assisted Reproductive Technology-Accomplishments and New Horizons, pp 231-254. Eds CJ De Jonge \& CLR Barratt. Cambridge: Cambridge University Press.

Kim YH, Haidl G, Schaefer M, Egner U \& Herr JC 2007 Compartmentalization of a unique ADT/ATP carrier protein SFEC (sperm flagellar energy carrier, AAC4) with glycolytic enzymes in the fibrous sheath of the human sperm flagellar principal piece. Developmental Biology 302 463-476.

Lalancette C, Faure RL \& Leclerc P 2006 Identification of the proteins present in the bull sperm cytosolic fraction enriched in tyrosine kinase activity: a proteomic approach. Proteomics 6 4523-4540.

Larsen L, Scheike T, Jensen TK, Bonde JP, Ernst E, Hjollund NH, Zhou Y, Skakkebaek NE \& Giwercman A 2000 Computer-assisted semen analysis parameters as predictors for fertility of men from the general population. The danish first pregnancy planner study team. Human Reproduction 15 1562-1567.

Leclerc P, de Lamirande E \& Gagnon C 1996 Cyclic adenosine $3^{\prime}, 5^{\prime}$ monophosphate-dependent regulation of protein tyrosine phosphorylation in relation to human sperm capacitation and motility. Biology of Reproduction 55 684-692.

Lefièvre L, Jha KN, de Lamirande E, Visconti PE \& Gagnon C 2002 Activation of protein kinase A during human sperm capacitation and acrosome reaction. Journal of Andrology 23 709-716.

Lefièvre L, Barratt CL, Harper CV, Conner SJ, Flesch FM, Deeks E, Moseley FL, Pixton KL, Brewis IA \& Publicover SJ 2003 Physiological and proteomic approaches to studying prefertilization events in the human. Reproductive Biomedicine Online 7 419-427.

Maher ER 2005 Imprinting and assisted reproductive technology. Human Molecular Genetics 14 R133-R138.

Makhlouf AA \& Niederberger C 2006 DNA integrity tests in clinical practice: it is not a simple matter of black and white (or red and green). Journal of Andrology 27 316-323.

Marquez B \& Suarez SS 2004 Different signalling pathways in bovine sperm regulate capacitation and hyperactivation. Biology of Reproduction 70 1626-1633.

Martinez-Heredia J, Estanyol JM, Ballesca JL \& Oliva R 2006 Proteomic identification of human sperm proteins. Proteomics $\mathbf{6}$ 4356-4369.

Miller D, Ostermeier GC \& Krawetz SA 2005 The controversy, potential and roles of spermatozoal RNA. Trends in Molecular Medicine 114 156-163.

Moseley FL, Jha KN, Bjorndahl L, Brewis IA, Publicover SJ, Barratt CL \& Lefièvre L 2005 Protein tyrosine phosphorylation, hyperactivation and progesterone-induced acrosome reaction are enhanced in IVF media: an effect that is not associated with an increase in protein kinase A activation. Molecular Human Reproduction 11 523-529. 
Moura AA, Chapman DA, Koc H \& Killian GJ 2006 Proteins of the cauda epididymal fluid associated with fertility of mature dairy bulls. Journal of Andrology 27 534-541.

Moura AA, Chapman DA \& Killian GJ 2007a Proteins of the accessory sex glands associated with the oocyte-penetrating capacity of cauda epididymal sperm from holstein bulls of documented fertility. Molecular Reproduction and Development 74 214-222.

Moura AA, Chapman DA, Koc H \& Killian GJ 2007 b A comprehensive proteomic analysis of the accessory sex gland fluid from mature Holstein bulls. Animal Reproduction Science 98 169-188.

Muller CH 2000 Rationale, interpretation, validation, and uses of sperm function tests. Journal of Andrology 21 10-30.

Naaby-Hansen S, Flickinger CJ \& Herr JC 1997 Two-dimensional gel electrophoretic analysis of vectorially labeled surface proteins of human spermatozoa. Biology of Reproduction 56 771-787.

Naz RK \& Rajesh PB 2004 Role of tyrosine phosphorylation in sperm capacitation acrosome reaction. Reproductive Biology and Endocrinology 2 75-87.

Nomura M \& Vacquier VD 2006 Proteins associated with soluble adenylyl cyclase in sea urchin sperm flagella. Cell Motility and the Cytoskeleton 63 582-590.

O'Flaherty C, de Lamirande E \& Gagnon C 2004 Phosphorylation of the arginine-X-X-(serine/threonine) motif in human sperm proteins during capacitation: modulation and protein kinase A dependency. Molecular Human Reproduction 10 355-363.

Ohmuro J \& Ishijima S 2006 Hyperactivation is the mode conversion from constant-curvature beating to constant-frequency beating under a constant rate of microtubule sliding. Molecular Reproduction and Development 73 1412-1421.

Osheroff JE, Visconti PE, Valenzuela JP, Travis AJ, Alvarez J \& Kopf GS 1999 Regulation of human sperm capacitation by a cholesterol efflux-stimulated signal transduction pathway leading to protein kinase A-mediated up-regulation of protein tyrosine phosphorylation. Molecular Human Reproduction 5 1017-1026.

Pacey AA 2006 Is quality assurance in semen analysis still really necessary? A view from the andrology laboratory Human Reproduction 21 1105-1109.

Pazour GJ, Agrin N, Leszyk J \& Witman GB 2005 Proteomic analysis of a eukaryotic cilium. Journal of Cell Biology 170 103-113.

Pilch B \& Mann M 2006 Large-scale and high-confidence proteomic analysis of human seminal plasma. Genome Biology 7 R40.

Pixton KL, Deeks ED, Flesch FM, Moseley FL, Bjorndahl L, Ashton PR, Barratt CL \& Brewis IA 2004 Sperm proteome mapping of a patient who experienced failed fertilization at IVF reveals altered expression of at least 20 proteins compared with fertile donors: case report. Human Reproduction 19 1438-1447.

Publicover SJ, Harper CV \& Barratt CLR $2007\left[\mathrm{Ca}^{2+}\right]_{i}$ signalling in sperm - making the most of what you've got. Nature Cell Biology 9 235-242.

Rifai N, Gillette MA \& Carr SA 2006 Protein biomarker discovery and validation: the long and uncertain path to clinical utility. Nature Biotechnology 24 971-983.

Robinson JN, Lockwood GM, Dalton JD, Franklin PA, Farr MM \& Barlow DH 1992 A randomized prospective study to assess the effect of the use of home urinary luteinizing hormone detection on the efficiency of donor insemination. Human Reproduction 7 63-65.

Seli E \& Sakkas D 2005 Spermatozoal nuclear determinants of reproductive outcome: implications for ART. Human Reproduction Update 11 337-349.

Sharpe RM \& Irvine DS 2004 How strong is the evidence of a link between environmental chemicals and adverse effects on human reproductive health? British Medical Journal 328 447-451.
Shetty J, Naaby-Hansen S, Shibahara H, Bronson R, Flickinger CJ \& Herr JC 1999 Human sperm proteome: immunodominant sperm surface antigens identified with sera from infertile men and women. Biology of Reproduction 61 61-69.

Shibahara H, Sato I, Shetty J, Naaby-Hansen S, Herr JC, Wakimoto E \& Koyama K 2002 Two-dimensional electrophoretic analysis of sperm antigens recognized by sperm immobilizing antibodies detected in infertile women. Journal of Reproductive Immunology 53 1-12.

Stein KK, Go JC, Lane WS, Primakoff P \& Myles DG 2006 Proteomic analysis of sperm regions that mediate sperm-egg interactions. Proteomics 6 3533-3543.

Steures P, van der Steeg JW, Hompes PG, Habbema JD, Eijkemans MJ, Broekmans FJ, Verhoeve HR, Bossuyt PM, van der Veen F, Mol BW \& Collaborative Effort on the Clinical Evaluation in Reproductive Medicine 2006 Intrauterine insemination with controlled ovarian hyperstimulation versus expectant management for couples with unexplained subfertility and an intermediate prognosis: a randomised clinical trial. Lancet 368 216-221.

Sutovsky P, Manandhar G, McCauley TC, Caamano JN, Sutovsky M, Thompson WE \& Day BN 2004 Proteasomal interference prevents zona pellucida penetration and fertilization in mammals. Biology of Reproduction 71 1625-1637.

Tash JS \& Means AR 1983 Cyclic adenosine 3',5' monophosphate, calcium and protein phosphorylation in flagellar motility. Biology of Reproduction 28 75-104.

Templeton A, Fraser C \& Thompson B 1990 The epidemiology of infertility in Aberdeen. British Medical Journal 301 148-152.

Tomlinson MJ, Kessopoulou E \& Barratt CL 1999 The diagnostic and prognostic value of traditional semen parameters. Journal of Andrology 20 588-593.

Visconti PE, Bailey JL, Moore GD, Pan D, Olds-Clarke P \& Kopf GS 1995a Capacitation of mouse spermatozoa. I. Correlation between the capacitation state and protein tyrosine phosphorylation. Development 121 1129-1137.

Visconti PE, Moore GD, Bailey JL, Leclerc P, Connors SA, Pan D, OldsClarke P \& Kopf GS 1995b Capacitation of mouse spermatozoa. II. Protein tyrosine phosphorylation and capacitation are regulated by a cAMP-dependent pathway. Development 121 1139-1150.

Visconti PE, Westbrook VA, Chertihin O, Demarco I, Sleight S \& Diekman AB 2002 Novel signalling pathways involved in sperm acquisition of fertilizing capacity. Journal of Reproductive Immunology 53 133-150.

Wild S, Roglic G, Green A, Sicree R \& King H 2004 Global prevalence of diabetess: estimates for the year 2000 and projections for 2030. Diabetes Care 27 1047-1053.

Williams AC \& Ford WC 2005 Relationship between reactive oxygen species production and lipid peroxidation in human sperm suspensions and their association with sperm function. Fertility and Sterility 83 929-936.

World Health Organization (WHO) 1999 WHO Laboratory Manual for the Examination of Human Semen and Sperm-Cervical Mucus Interaction, Cambridge, United Kingdom: Cambridge University Press.

Zhang Z, Kostetskii I, Moss SB, Jones BH, Ho C, Wang H, Kishida T, Gerton GL, Radice GL \& Strauss JF III 2004 Haploinsufficiency for the murine orthologue of Chlamydomonas PF20 disrupts spermatogenesis. PNAS 101 12946-12951.

Zinaman MJ, Brown CC, Selevan SG \& Clegg ED 2000 Semen quality and human fertility: a prospective study with healthy couples. Journal of Andrology 21 145-153.

Received 17 November 2006

First decision 4 January 2007

Accepted 2 February 2007 